\title{
Examining the Relation Between the Physical Features of 10-12 Year-Old Male Tennis Players and the Speeds of the Service Strikes
}

\author{
Yunus Emre BAGIS ${ }^{1}$ \\ ${ }^{1}$ Department of Coaching Education, Süleyman Demirel University, Isparta, Turkey \\ Correspondence: Yunus Emre BAGIS, Department of Coaching Education, Süleyman Demirel University, Isparta, \\ Turkey. E-mail: yunusemrebagis@hotmail.com
}

Received: December 30, 2019 Accepted: January 30, 2020 Online Published: February 25, 2020

doi:10.5539/jel.v9n2p134 URL: https://doi.org/10.5539/jel.v9n2p134

\begin{abstract}
The purpose of the present study was to examine the relation between the physical characteristics of male tennis players who were aged 10-12 and their service strike speeds. A total of 13 licensed male tennis players (mean age $10.1 \pm 0.1$ years, mean height $1.46 \pm .06 \mathrm{~m}$, mean body weight $38.7 \pm 1.8 \mathrm{~kg}$, mean sporting age $4.7 \pm 0.3$ years) who played at Middle East Technical University Tennis Club participated in the study. The demographic, anthropometric, (width, length, circumference, and subcutaneous fat) and ball speed measurements of the tennis players were taken and recorded. The data were analyzed by using the "Descriptive Statistics" and "Pearson Correlation" in the Statistical Package Program. When length measurements were examined, it was determined that although there was a positive relation between ball speeds and hand length $(\mathrm{p}<0.05)$; a negative relation was detected between the other measurements $(p>0.05)$. When the width measurements were evaluated, it was determined that although there was a positive relation between ball speeds and chest, elbow and wrist widths $(p<0.05)$; a negative relation was detected between the other measurements $(p>0.05)$. In terms of the circumferences, although a positive relation was detected between ball speeds and arm contraction, chest, chest inspiration, and chest expiration circumference $(\mathrm{p}<0.05)$; a negative relation was detected between the other circumference measurements $(\mathrm{p}>0.05)$. When subcutaneous fat measurements were examined, it was determined that there was a negative relation between ball speeds $(\mathrm{p}>0.05)$. As a result, when previous studies and literature were examined, it was determined that many studies emphasized that the factors that affect the service speed of young tennis players have a positive relationship with age. It is obvious that the strength features, and depending on this, anthropometric properties improve with age. It is considered that special force and technical training drills, regardless of the age category, may affect the speed and accuracy of the service strike in tennis. Our study offers a different perspective to coaches on this subject.
\end{abstract}

Keywords: tennis, physical, service, speed

\section{Introduction}

Service strike is one of the most important strikes in tennis and is considered to be one of the most important factors that affect the outcomes of the game. In this respect, examining the relationship between the speed and success of the service of the tennis player and the ranking is becoming increasingly important (Perez \& Nussbaum, 2006). The effect of the service on tennis was examined with various devices and different scientific approaches (biomechanical measurements, motor control and learning, physiology, etc.). In recent years, studies conducted on tennis players have shown that muscular strength has a significant effect on the effectiveness of service together with various rotational variables of the upper-extremity joints. When the close relation of muscular strength with body structure is considered, the importance of anthropometric and somatotype features in tennis becomes to the forefront (Antunez et al., 2012).

The speed of the ball in service strikes depends on the integrity of complex interdependent anthropometric, motoric and biomechanical factors. Among these factors, the physical structure, strength, the width of joint movement, the speed of the joints of the tennis player and the speed of the racket during the service are very important (Reid et al., 2003). Limited studies investigated the relation between ball speeds and the physical fitness and biomechanical parameters in service strikes. Cohen et al. (1994) conducted a study on tennis players with good service strike techniques and found a significant relation between ball speeds and wrist flexion, shoulder flexion and internal rotation joint movement widths. In previous studies, it was acknowledged that there is a low-level 
relation between ball speed and upper extremity isokinetic force (Ellenbecker et al., 1991; Cohen et al., 1994). The recovery of force during a service strike is achieved by the kinetic chain that is produced by the body. With the starting of the service movement, the force that is produced by the leg muscles is transferred to the waist and shoulder, to the elbow, to the wrist, and then to the racquet (Elliott et al., 1995; Bahamonde, 2000).

In many previous studies, the selection of talented players specific for sports was primarily made by considering physical parameters. Anthropometric measurements are important in the analysis of movements and in determining who is more mechanically advantageous. In recent years, there have been significant technical and tactical changes in tennis, which has increased the need to study the physical performance of tennis players. The scientific literature on tennis is mostly on the physiological, biomechanical and health of the player dimensions of tennis, and there is a limited number of studies conducted on the physical characteristics of young tennis players (Munoz et al., 2007). In this context, the purpose of the present study was to examine the relation between the physical characteristics of male tennis players who were aged 10-12 and service strike speeds.

\section{Method}

\subsection{Participants}

The study group consisted of 13 male tennis players licensed at Ankara Middle East Technical University Tennis Club (mean age $10.15 \pm .37$ years, mean height $1.46 \pm .06 \mathrm{~m}$, mean body weight $38.77 \pm 6.67 \mathrm{~kg}$, mean sporting age $4.76 \pm 1.16$ years). The players and their parents were informed about the purpose of the study before the test and about the possible risks that might occur during exercises. "Parental Consent Form" was approved by all parents, and the players were thus allowed to participate in the study. In addition, the players were warned to avoid any drugs or forcing physical activities that could affect body metabolism.

\subsection{Measures}

\subsubsection{Height Measurements}

A metal height scale that had a $0.1 \mathrm{~m}$ sensitivity was used for measurements.

\subsubsection{Body Weight Measurements}

The measurements were made with an electronic scale that had a sensitivity of $0.5 \mathrm{~kg}$ when the players wore only shorts and T-shirts and bare feet.

\subsubsection{Height Measurements}

A bendable and non-elastic measuring tape that had a $7-\mathrm{mm}$ width and a sensitivity of 0.1 was used.

\subsubsection{Circumference Measurements}

A bendable and non-elastic measuring tape that had a $7-\mathrm{mm}$ width and a sensitivity of 0.1 was used.

\subsubsection{Width Measurements}

A doe-foot caliper was used for the measurement in certain reference points of the body.

\subsubsection{Subcutaneous Fat Measurements}

Skinfold Caliper with a $0.1 \mathrm{~mm} / \mathrm{HG}$ sensitivity was used. The measurements were made on the dominant side of the body. Each measurement was repeated twice, and the average value was recorded.

\subsubsection{Ball Speed Measurements}

In measuring the ball speed, all services were used in an indoor tennis court for the purpose of controlling the effects of the air. The subjects warmed-up until they reached the level of maximal service speed. Three minutes after the warm-up of the players, the test stage was initiated, and the participants were asked to serve at 8 maximal speeds. The Sports Radar and Power Madd were used to measure the ball speeds. The radar that was used in measuring the ball speeds was fixed to the middle (net) line service return point. In line with tennis rules, the services must be thrown to the cross-service box, backhand, and service welcome (return) point; and if the ball is thrown out of the net or service box, it is not recorded as service. The feedback of the speed was reported to the players to obtain maximal effort. All services are thrown to the left service box (right side) for right-handed players, and to the right service box (left side) for left-handed players. All tennis players were instructed to use the straight service technique. The services were evaluated by two tennis coaches. For data analysis, the fastest of the 8 services $(\mathrm{km} / \mathrm{h})$ that the players achieved at maximum speed were analyzed and recorded as the maximal service (MaxS) (Cohen, 1994).

\subsection{Statistical Analysis}

The "Descriptive Statistics" and "Correlation Analysis" were used in the statistical package program for the 
analysis of the data. The significance level was taken as $\mathrm{p}<05$.

\section{Findings}

Table 1. The relation between the demographic characteristics and service speeds of the tennis players

\begin{tabular}{lllll}
\hline & N & Ave \pm SD & r & p \\
\hline Age (year) & 13 & $10.15 \pm 0.37$ & $\mathbf{. 6 7 5 *}$ & $\mathbf{. 0 1 1}$ \\
Height (m) & & $1.46 \pm 0.06$ & .439 & .133 \\
Body Weight (kg) & & $38.77 \pm 6.67$ & .439 & .134 \\
Sporting Age (year) & & $4.76 \pm 1.16$ & $\mathbf{. 6 2 1 *}$ & $\mathbf{. 0 2 3}$ \\
Service speed (km/hour) & & $104.15 \pm 15.36$ & 1 & 1 \\
\hline
\end{tabular}

When Table 1 is examined, it is seen that although there was a positive relationship between the ages, sports ages, and the service speeds of tennis players $(\mathrm{p}<0.05)$; no relations were detected with other features $(\mathrm{p}>0.05)$.

Table 2. The relation between the length measurements and service speed of the tennis players

\begin{tabular}{lllll}
\hline & Ave. & SD & r & p \\
\hline Height & 1.46 & .06 & .439 & .133 \\
Arm & 26.00 & .95 & .172 & .575 \\
Forearm & 21.23 & .83 & .289 & .339 \\
Hand & 15.57 & .18 & $.737^{*}$ &. $\mathbf{0 0 4}$ \\
Thigh & 44.38 & 6.27 & .258 & .395 \\
Leg & 34.00 & 2.38 & .214 & .482 \\
Feet & 23.65 & 4.09 & .211 & .490 \\
\hline
\end{tabular}

When Table 2 is examined, it is seen that although there was a positive relationship between ball speeds and hang lengths in service shots $(p<0.05)$; there was a negative relation between the other measurements $(p>0.05)$.

Table 3. The relation between width measurements of the tennis players and service speeds

\begin{tabular}{lllll}
\hline & Ave. & SD & r & p \\
\hline Shoulder & 32.38 & 1.66 & -.068 & .826 \\
Chest & 19.69 & 1.93 & $\mathbf{. 5 5}^{*}$ & $\mathbf{. 0 4 9}$ \\
Chest Depth & 16.38 & 1.50 & .301 & .318 \\
Elbow & 5.76 & 0.43 & $\mathbf{. 5 6 0 ^ { * }}$ & $\mathbf{. 0 4 7}$ \\
Hand wrist & 5.53 & 0.51 & $\mathbf{. 5 6 3} *$ & $\mathbf{. 0 4 5}$ \\
Hand & 6.92 & 0.49 & .244 & .423 \\
Hip & 23.30 & 1.93 & .147 & .631 \\
Knee & 8.53 & 1.19 & .027 & .931 \\
Ankle & 6.53 & 0.51 & .156 & .611 \\
Feet & 7.30 & 0.75 & -.142 & .644 \\
\hline
\end{tabular}

When Table 3 is examined, it is seen that there was a positive relationship between the ball speeds and chest, elbow, hand wrist width $(p<0.05)$, and a negative relation was detected between other width measurements $(p>0.05)$. 
Table 4. The relation between the circumference measurements of the tennis players and service speed

\begin{tabular}{lllll}
\hline & Ave. & SD & r & p \\
\hline Shoulder & 85.31 & 4.66 & .358 & .230 \\
Right Shoulder & 25.57 & 2.67 & .351 & .239 \\
Left Shoulder & 24.61 & 2.07 & .236 & .437 \\
Arm & 20.88 & 2.59 & .358 & .229 \\
Arm Contraction & 22.76 & 2.92 & $\mathbf{. 5 9 6}$ & $\mathbf{. 0 4 2}$ \\
Forearm & 20.30 & 1.48 & .349 & .241 \\
Forearm Contraction & 21.92 & 1.81 & .350 & .241 \\
Chest & 71.00 & 7.00 & $\mathbf{. 5 7 2 *}$ & $\mathbf{. 0 4 9}$ \\
Chest Inspiration & 75.15 & 6.38 & $\mathbf{. 5 5 5 ^ { * }}$ & $\mathbf{. 0 4 4}$ \\
Chest Expiration & 69.15 & 7.26 & $\mathbf{. 5 6} 0^{*}$ & $\mathbf{. 0 4 7}$ \\
Abdomen & 66.31 & 9.34 & .410 & .164 \\
Hip & 76.23 & 8.58 & .309 & .305 \\
Thigh & 46.08 & 8.07 & .218 & .473 \\
Leg & 29.61 & 2.32 & .225 & .458 \\
\hline
\end{tabular}

When Table 4 is examined, it is seen that there was a positive relation between ball speeds and arm contraction, chest, chest inspiration, chest expiration circumference measurement scores $(\mathrm{p}<0.05)$; and a negative relation was found between the other circumference measurements $(\mathrm{p}>0.05)$.

Table 5. The relation between the subcutaneous fat measurements and service speeds of tennis players

\begin{tabular}{lllll}
\hline & Ave. & SD & r & p \\
\hline Biceps & 8.64 & 4.24 & .198 & .517 \\
Triceps & 13.15 & 4.53 & -.140 & .648 \\
Subscapularis & 9.19 & 4.59 & .245 & .420 \\
Pectoral & 9.52 & 4.59 & .344 & .250 \\
Abdomen & 12.79 & 6.32 & .210 & .492 \\
Quadriceps & 15.92 & 4.84 & .165 & .590 \\
Calf & 14.14 & 2.72 & .070 & .819 \\
\hline
\end{tabular}

When Table 5 is examined, it is seen that a negative relation was found between the ball speeds and subcutaneous fat measurements ( $\mathrm{p}>0.05)$.

\section{Discussion}

This study was conducted to examine the relation between the physical characteristics and service strike speeds of tennis players who were between 10-12 years of age. Licensed male tennis players $(n=13)$ from Middle East Technical University Tennis Sports Club participated in the study.

In our study, the mean age of the tennis players was $10.15 \pm .37$ years, the mean height was $1.46 \pm .06 \mathrm{~m}$, the mean body weight was $38.77 \pm 6.67 \mathrm{~kg}$, and the mean sporting age was $4.76 \pm 1.16$ years.

Each excessive weight gained in the body changes the location of the center of gravity of the body (Mengütay, 1999). This can disrupt the balance of the body during service. An effective service is a parameter that is related directly with height, and the training age refers to the experience in service (Elliott et al., 2003). Since tall tennis players can meet the ball higher than short players, they seem to have an advantage in this respect, because they form a greater angle, which means that the ball is hit faster. To avoid being attached to the net, straight services must be shot at a height of a minimum of $254 \mathrm{~cm}$. A ball that is hit at a height of $254 \mathrm{~cm}$ can reach a maximum speed of $179 \mathrm{~km} / \mathrm{h}$ because of its vertical angle range (Brody, 1988). Kleinöder (1997) conducted a study on tennis players of different levels who had similar heights and reported that the heights of tennis players around the world to meet the ball was $274 \mathrm{~cm}$ and that the German league players had this value $16 \mathrm{~cm}$ lower than this value.

In the present study, a positive relation was detected between the ball speeds, ages and sports ages in service strikes of the players $(\mathrm{p}<0.05)$. A negative relation was detected between the ball speeds, heights and weights of the players in service strikes $(p>0.05)$. The reason for this negative relation is that the number of tennis players in the study was from the younger age group. It is considered that mostly motoric features affect service strike rates. In his study with the title "Examining the Relation between the Speed of Ball and Physical Fitness and Biomechanical Characteristics of Tennis Players in Tennis Service", Gelen et al. (2009) reported that the average age of tennis players was 18.4 
years, the average height was $182.3 \mathrm{~cm}$, the average body weight was $72.2 \mathrm{~kg}$, the average sporting age was 9.5 , and the mean service speed was 145.0. In this study, it was determined that there was a relation between the speed of the ball and the heights of the players $(p<0.01)$, and the training ages $(p<0.05)$ in the service strikes of the tennis players. They found no significant relations between the ball speeds, ages and body weights. The reason why the findings of Gelen et al. and ours differ is the age between the study groups, and depending on this, the difference in force formations. The physical fitness values, which include physical, physiological and anthropometric characteristics of players, are very important in player selection. The multiple-joint kinetic chain, which is specific to the tennis service, requires optimal strength, flexibility, timing and coordination of many parts of the human body. For this reason, the performance of the service depends on the complexity and integrity of many interdependent factors (Weber, 1982; Ferrauti et al., 2002; Treiber et al., 1998). The high-speed muscle strength, which is an integral part of tennis service, requires the transfer of the force from the legs and the body to the arms at the appropriate level and time (Roetert et al., 1996, Groppel, 1992).

When length measurements were examined in our study, although it was determined that there was a positive relation between ball speeds and hand length $(p<0.05)$; a negative relation was detected between the other length measurements $(\mathrm{p}>0.05)$. When the width measurements were examined, it was determined that although there was a positive relation between ball speeds and chest, elbow and wrist widths $(\mathrm{p}<0.05)$; a negative relation was detected between other width measurements ( $p>0.05$ ). In the relation between ball speeds and arm contraction, chest, chest inspiration, chest expiration circumference $(p<0.05)$, it was determined that there were positive relations between other circumferential measurements $(\mathrm{p}>0.05)$. When the subcutaneous fat measurements were examined, it was determined that there was a negative relation between ball speeds ( $p>0.05)$.

Avar et al. (2013) conducted a study with the title "Examining the Relation between the Anthropometric and Somatotype Characteristics of Tennis Players Aged 10-12 in terms of Service Speeds and Turkish Classification Ranking", and reported statistically significant differences between the ages of male tennis players and their service speeds $(\mathrm{r}=0.60 ; \mathrm{p}<0.01)$. It was determined that the service rates and Turkey Classification Ranking were found to be parallel to the age at which the players started tennis. For this reason, it may be argued that the experience gained by tennis players in terms of age affects performance and success positively in sports. Again, in the same study that was conducted by Avar et al. in 2013, they reported a significant and statistical relationship between the heights of the female tennis players $(\mathrm{r}=0.61 ; \mathrm{p}<0.05)$, their body weights $(\mathrm{r}=0.66 ; \mathrm{p}<0.05)$ and service speeds. Avar et al. (2013) conducted a study with the title "Examining the Relation between Anthropometric and Somatotype Characteristics of 10-12-Year-Old Tennis Players, and the Service Speeds and Turkish Classifications, and reported that they found a positive relation between heights and service speeds of the women tennis players $(r=0.66 ; p<0.05)$ and male tennis players $(r=0.58 ; p<0.01)$. The reason why this study has similarities with ours is that the physical development of female players is faster than male players. We believe that the reason why it is different from the study of ours is that there are more study groups.

\section{Conclusion}

As a result, when the present study and literature were examined, it was determined that there is a positive relationship between service speeds and ages, which are among the factors that affect the service speeds of small tennis players. It is obvious that the strength characteristics and physical properties develop with age. It is considered that special force and technical training drills, which will be carried out in all age categories without bringing physical properties to the forefront, may have a more positive effect on the strike speed and accuracy of service. Future studies considering this context may give coaches a different perspective on the speed of service strikes.

\section{References}

Antunez, R. M., Hernandez, F. J. M., Garcia, J. P. F., Vaillo, R. R., \& Arroyo, J. S. D. (2012). Relationship between motor variability, accuracy and ball speed in tennis serve. Journal of Human Kinetics, 33(1), 45-53. https://doi.org/10.2478/v10078-012-0043-3

Bahamonde, R. (2000). Changes in angular momentum duringthetennisserve. Journol of Sport Sciences, 18, 579 592. https://doi.org/10.1080/02640410050082297

Cohen, D. B., Mont, M. A., Campbell, K. R., Vogelstein, B. N., \& Loewy, J. W. (1994). Upper extremity physical factor saffecting tenis servevelocity. The American Journal of Sports Medicine, 22(6), 746-750. https://doi.org/10.1177/036354659402200604

Durgun, B., \& Dere, F. (1994). Functional Anatomy for Sports Education. Adana: Schools Market Publication Distribution.

Ellenbecker, T. S. (1991). A total arm strength isokinetic profile of highly skilled tenis players. Isokinetic and 
Exercise Science, 1, 9-21. https://doi.org/10.3233/IES-1991-1103

Elliott, B., Marshall, R. N., \& Noffal, G. (1995). Contributions of upper limb segment rotations during the power serve in tennis. Journal of Applied Biomechanics, 11, 433-442. https://doi.org/10.1123/jab.11.4.433

Elliott, B., Reid, M., \& Crespo, M. (2003). Biomechanics of Advanced Tennis. International Tennis Federation, UK.

Ferrauti, A., Maier, P., \& Weber K. (2002). Tennis training. Meyer und Meyer Verlag, Deutchland.

Groppel, J. L. (1992). High Tech Tennis. Champaign, IL: Human Kinetics, USA.

Heymsfield, S., Lohamn, T., Wang, Z. M., \& Going, S. (2005). Human body composition (2nd ed.). Human Kinetics.

Kleinöder, H. (1997). Quantitative Analysen von Sclagtechniken im Tenis, Intra und Interindividuelle Studien Bei Spielern Unterschidlichen Leistungsniveaus. Deutsche Sport Hochschule Köln, Institut für Trainings und Bewegungslehre, Dissertation.

Mengütay, S. (1999). Movement Development and Sports in Preschool and Primary Schools (pp. 3-6). Tutibay Publishing, Ankara.

Munoz, C. S., Sanz, D., \& Zabala, M. (2007). Anthropometric characteristics, body composition and somatotype of elite junior tennis players. British Joournal of Sports Medicine, 41, 793-799. https://doi.org/10.1136/bjsm.2007.037119

Perez, M. A., \& Nussbaum, M. A. (2006). Posture and motionvari ability in non-repetitivem annual material shandlingt asks. Human Movement Sciences, 25(3), 409-421. https://doi.org/10.1016/j.humov.2006.02.003

Reid, M., Elliott, B., \& Alderson, J. (2007). Shoulder joint loading in thehigh-performance flat and kick serves. British Journal of Sports Medicine, 41, 884-889. https://doi.org/10.1136/bjsm.2007.036657

Roetert, E. P., McCormick, T. J., Brown, S. W., \& Ellenbecker, T. S. (1996). Relation between isokenetic and functional trunk strength in elite junior tenis players. Isokinetic and Exercise Sciences, 6, 15-20. https://doi.org/10.3233/IES-1996-6103

Treiber, F. A., Lott, J., Duncan, J., Slavens, G., \& Davis, H. (1998). Effects of theraband and lightweight dumbbell training on shoulder rotation torque and serve perfomance in college tenis players. American Journal of Sports Medicine, 26(4), 510-515. https://doi.org/10.1177/03635465980260040601

Weber, K. (1982). Tennis-Fitness, Gesundheit, Training und Sportmedizin. BLV Verlagsgeselschaft. Deurchland.

\section{Copyrights}

Copyright for this article is retained by the author, with first publication rights granted to the journal.

This is an open-access article distributed under the terms and conditions of the Creative Commons Attribution license (http://creativecommons.org/licenses/by/4.0/). 